\title{
MECHANISTIC STUDIES IN THE SIMULTANEOUS FLOW AND ADSORPTION OF POLYMER-COATED LATEX PARTICLES ON INTESTINAL MUCUS I: METHODS AND PHYSICAL MODEL DEVELOPMENT*
}

\author{
C.L.C. Teng
}

College of Pharmacy, The University of Michigan, Ann Arbor, MI 48109 (U.S.A.)

N.F.H. Ho**

Drug Delivery Systems Research, The Upjohn Company, Kalamazoo, M1 49001 (U.S.A.)

The adsorption of particles and concurrent steady-state flow of a dilute suspension from an infinite reservoir over the mucous surface of intestinal strips were quantitatively studied. The micronsize particle systems included negatively charged poly (vinyltoluene) and hydroxylated Dynosphere ${ }^{\circledast}$ particles with and without a positively charged polybrene polymer coated layer. The suspensoids were characterized by zèta potential measurements. An in vitro setup and technique likened to a thin falling liquid film system was developed wherein an excised intestinal segment cut lengthwise is spread on a plastic flute and positioned at an incline, and a suspension is allowed to flow down the intestinal strip. The falling liquid film was estimated to be $54 \mu \mathrm{m}$ in thickness from nonsteady-state flow kinetic experiments. Particle concentrations entering the segment from the dilute suspension reservoir and leaving the intestinal segment were determined with the Coulter counter to quantify the steady-state fraction of particles adsorbed as they relate to intestinal length, flow rate, ionic strength, zèta potential and particle concentration. The flowing liquid film technique was found to be quantitatively sensitive and, consequently, allowed one to focus on the mechanism of the approach of micron-size particles to the mucous surface without the major concern of particle flocculation in the bulk liquid.

The logarithm of the fraction of nonadsorbed particles remaining in the liquid film decreased linearly with intestinal length at all flow rates employed. The fraction adsorbed decreased with increasing flow rates on account of the shorter transit times. The steady-state region of the fraction of nonadsorbed particles remaining versus time plots persisted for a relatively long time indicating the existence of a particle concentration gradient along the length of the intestinal strip. The fact that the fraction of particles adsorbed was not affected by particle concentrations ranging from $4.5-14 \times 10^{6}$ particles per ml suggests that there is sufficiently available unoccupied surface area for incoming particles to be adsorbed onto mucus. It has been estimated that no more than 5\% of the area of the intestinal strip is occupied by adsorbed particles. Failure to desorb particles from the mucous surface by perfusing the intestinal segment indicates tight binding between the particles and mucus. A physical model was deduced from the experimental results wherein the steady-state fraction of adsorbed particles is related to length of the intestinal strip, flow rate and mass transfer-adsorption coefficient.

The mass transfer resistances of negatively charged particles decreased with the addition of sodium chloride and approached the minimum resistance obtained by the positively charged, polybrenecoated latex particles, whose mass transfer resistance was independent of electrolyte concentra- 
tion. This supports a mechanism involving the diffusion of the negatively charged particles within an electrostatic field of force as the particles approach the negatively charged mucous surface. Passage of particles over the potential energy barrier is required for the successful collision and tight binding with mucus.

\section{INTRODUCTION}

The flow and transit time of particles across the small intestine have a marked influence on the completeness of intestinal absorption of suspensions and on the efficiency in achieving oral bioavailability. This was recently highlighted when particle and fluid flow, dissolution kinetics (particle size, solubility, aqueous diffusivity), slurry density, membrane permeability and intestinal length were interrelated and quantitatively examined within the theoretical framework of the anatomical reserve length for small intestinal absorption [1].

In fasting individuals the fluid flow velocity ranges from 0.5 to $5 \mathrm{~cm} / \mathrm{min}$, depending upon the time at which the fluid flow marker is introduced in the small intestine and the motility phase at which the segment is governed by the interdigestive motor complex. There are indications that the average flow velocities of small pellets are similar, if not somewhat slower, to that of fluid. It has been estimated that if the particle velocity is about $1 \%$ of the usual range of fluid velocities, the bioavailability of oral suspensions of lipophilic drugs from the small intestine is assured. The question is whether one can design particles to have their own velocities which are relatively independent of variations in fluid velocities.

Studies on the adherence of polymer surfaces to mucus lining biological membranes have generally taken static approaches in order to elucidate mechanisms of adhesion. Park and Robinson [2] studied bioadhesion by measur-

\footnotetext{
*Paper presented at Third International Symposium on Recent Advances in Drug Delivery Systems, February 24-27, 1987, Salt Lake City, UT, U.S.A.

**To whom correspondence should be addressed.
}

ing the force required to separate hydrated polymer preparations from the mucous layer of excised rabbit stomach tissue. While there appears to be no single mechanism to explain the adhesion phenomena, adhesion occurs categorically by electrostatic attraction, hydrogen and hydrophobic bonding, and physical entanglement as the polymer and mucus penetrate each others' domain. Strong adhesive properties are generally observed when polymers possess hydrophilic functional groups and are highly charged [3,4]. Neutral polymers exhibit less adhesion as compared to charged polymers.

The overall objective of this research is to establish the basic framework in mechanistic understanding of the adhesion between polymer and small intestinal mucus. The major thrust of the present project is to: (a) develop quantitative experimental approaches, (b) understand rate determining steps and factors on a mechanistic basis, (c) put physical chemical variables into quantitative relationships, and (d) develop a mathematical physical model. To accomplish the specific aims, polymers which are known to have bioadhesive properties and can be coated on latex particles will be used in connection with the intestinal tract of the rat.

\section{EXPERIMENTAL}

\section{Materials}

The particles used were poly (vinyltoluene) (PVT, $2 \mu \mathrm{m} \pm 0.0135$ s.d. diameter, 1.027 $\mathrm{gm} / \mathrm{cm}^{3}$ density, Dow Chemical, Midland, MI), and hydroxylated Dynosphere ${ }^{\circledR}(3 \mu \mathrm{m} \pm 0.15$ s.d. diameter, $1.05 \mathrm{gm} / \mathrm{cm}^{3}$ density, Dyno Industries, Oslo, Norway). Dynosphere latex 
particles are known as core/shell particles. The core is made of polystyrene and the shell is an acrylic co-polymer. The exact composition of the shell part is unclear. However, it is known that the hydroxylated particles have hydroxyl groups. Prior to use, particles were cleaned as described in the next section.

Polybrene ( $\mathrm{M}_{\mathrm{w}}$ 5,000, Aldrich, Chicago, IL. ), also known as hexadimethrine bromide, was used as a positively charged polymer with quaternary ammonium groups and used without further purification. Tritium-labeled polyethylene glycol (PEG-4000, New England Nuclear, Boston, MA.) was used as received.

Buffer formulations having varied ionic strength are found in Table I. All buffers were at pH 7.5 and adjusted to iso-osmotic conditions (305 mosm $/ \mathrm{Kg}$ ).

\section{Preparation and characterization of primary latex particles}

Poly(vinyltoluene) latex particles were cleaned to remove surfactants and ions adsorbed onto the particle surface. First, the latex particles were suspended in a cleaning solvent (distilled deionized water or $75 \%$ alcohol) and centrifuged for $15 \mathrm{~min}$ ( $3000 \mathrm{rpm}$ for the $75 \%$ alcohol case and $5000 \mathrm{rpm}$ for distilled deionized water case). After decanting the supernatant liquid, the pellet was resuspended in the washing solvent by sonication for $30 \mathrm{~s}$ in a water bath-type sonicator (Model B-12, Branson, Shelton, Conn.) and centrifuged again. These cleaning procedures were performed three times with distilled deionized water, then twice with $75 \%$ alcohol, and finally three times with distilled deionized water. The clean latex particles were stored in distilled deionized water in a dialysis bag, and the water was changed daily.

Hydroxylated Dynosphere ${ }^{\circledR}$ particles were cleaned by suspending the particles in distilled deionized water and centrifuged for $10 \mathrm{~min}$ at $3000 \mathrm{rpm}$. The supernatant was decanted and the pellet was resuspended in a small amount of distilled deionized water. After the cleaning procedures were performed, the zèta potentials of all particles were measured by an electrophoretic mobility instrument (Laser-Zee, Model 501, Pen Kem, Bedford Hill, NY).

\section{Preparation of polymer-coated latex suspensions}

In the preparation of a polymer-coated latex suspension, a clean latex suspension was centrifuged and the supernatant was decanted. A known volume of $1 \%$ polybrene polymer solution was added to the latex particles such that the final particle concentration was about $5 \times 10^{8}$ particles per $\mathrm{ml}$. This primary suspension was stirred at least for two hours. Prior to use, the suspension was sonicated for $1 \mathrm{~min}$ to deaggregate the particles. The polymer-coated particle suspensions were made fresh on the day of the experiments.

To further prepare the polybrene-coated PVT and polybrene-coated hydroxylated Dynosphere particles in the buffer solutions varying in ionic strenght, an aliquot of the primary coated suspension in water was directly transferred into a beaker containing the buffer solution to give about $5 \times 10^{6}$ particles per $\mathrm{ml}$. Subsequently, the suspension was sonicated for $30 \mathrm{~s}$ and used $15 \mathrm{~min}$ later.

\section{Determination of latex particle concentra- tions with the coulter counter}

The concentration of latex particles was determined using a Coulter counter (model F. Coulter Electronic Inc., Hialeah, FL) and 30 $\mu \mathrm{m}$ aperture tube. The particles were diluted in normal saline, which was previously filtered through a $0.45 \mu \mathrm{m}$ membrane filter (MF disc filter, Milipore Corp. Bedford, MA.). The counts were between 20,000 to 30,000 particles per $0.5 \mathrm{ml}$. Coincident errors were minimal at these concentrations. Calibrations of the Coulter counter were done using monodispersed 2 $\mu \mathrm{m}$ and $3 \mu \mathrm{m}$ latex spheres. 


\section{Flocculation kinetics}

Flocculation kinetic experiments were carried out for all uncoated and polymer-coated latex particles dispersed in $\mathrm{pH} 7.5$ phosphatesodium chloride-urea buffer solutions described in Table 1 . To $80 \mathrm{ml}$ of the buffer solution in a $100 \mathrm{ml}$ beaker, an aliquot of the stock concentrate of particles was added to yield about $1 \times 10^{7}$ particles per $\mathrm{ml}$. The resulting suspension was sonicated for $30 \mathrm{~s}$ and then allowed to quiet down. It remained unstirred through the course of the experiment. Samples of $0.5 \mathrm{ml}$ were taken every $20 \mathrm{~min}$ for a period of $80 \mathrm{~min}$ with the aid of $1 \mathrm{ml}$ wide bore, blow-out, transfer pipettes in which the tips were $2 \mathrm{~cm}$ below the surface of the liquid. Care was taken not to disturb the master suspension during the sample withdrawal. With the tip of the pipette under the surface of $100 \mathrm{ml}$ normal saline, the $0.5 \mathrm{ml} \mathrm{sam}$ ple was slowly drained while stirring gently. Subsequently, it was counted using the Coulter counter and a $30 \mu \mathrm{m}$ aperture tube. No background corrections were necessary since the normal saline diluting solution was previously filtered through a $0.45 \mu \mathrm{m}$ filter.

\section{Preparation of intestinal segments}

Male, Sprague-Dawley rats weighing between 275 and 325 grams were used. Nonfasted rats were anesthetized with $20 \%$ urethane, $1.2 \mathrm{ml}$ i.p. twice at $15 \mathrm{~min}$ intervals. After making a midline abdominal incision of the skin, the small intestine was exposed and a segment of desired length was excised. The lumen was then cleansed with normal saline and a $30 \mathrm{ml}$ syringe. Adhering coagulated blood and fat on the external surface of the gut were removed with forceps. Subsequently, the segment was cut lengthwise with surgical scissors, and immediately spread out on the Tygon flute for the falling liquid film experiment.

\section{Falling liquid film method}

A schematic description of the falling film perfusion system is shown in Fig. 1. The system consists of four parts: (a) a single drive syringe pump, (b) supporting platform for the intestinal segment, (c) adjustable jack, and (d) collector for the liquid effluent.

In the pump system, a $10 \mathrm{ml}$ syringe was used for the perfusion fluid. Tygon tubing, $1 / 8$ inch i.d., was connected to the syringe and the tip of the outlet was securely placed and centered just above the surface of the intestine. The intestinal segment was supported by a flute prepared by cutting open the Tygon tubing, 1 inch i.d., and the length of the flute was cut exactly according to the desired length of intestinal segment. In turn, the flute was supported by a platform composed of a plastic foam board. The board rested on the edge of the pump, and the angle of inclination was adjusted by a laboratory jack.

To remove any loosely-held mucus, the excised intestinal segment mounted on the

TABLE 1

Iso-osmotic $\mathrm{pH} 7.5$ buffer formula and their ionic strengths

\begin{tabular}{|c|c|c|c|c|}
\hline Buffer ${ }^{A}$ & $\mathrm{NaH}_{2} \mathrm{PO}_{4} \cdot \mathrm{H}_{2} \mathrm{O}^{\mathrm{a}}$ & $\mathrm{NaCl}^{\mathrm{a}}$ & Urea $^{a}$ & Ionic Strength $(M)$ \\
\hline $7.5 \mathrm{mM} \mathrm{NaH} \mathrm{PO}_{4} \cdot \mathrm{H}_{2} \mathrm{O}$ & 1.0349 & 9.0 & 0 & 0.1650 \\
\hline $7.5 \mathrm{mM} \mathrm{NaH}{ }_{2} \mathrm{PO}_{4} \cdot \mathrm{H}_{2} \mathrm{O}$ & 1.0349 & 4.5 & 8.150 & 0.0882 \\
\hline $7.5 \mathrm{mM} \mathrm{NaH} \mathrm{PO}_{4} \cdot \mathrm{H}_{2} \mathrm{O}$ & 1.0349 & 3.0 & 10.867 & 0.0625 \\
\hline $7.5 \mathrm{mM} \mathrm{NaH}{ }_{2} \mathrm{PO}_{1} \cdot \mathrm{H}_{2} \mathrm{O}$ & 1.0349 & 1.0 & 14.489 & 0.0283 \\
\hline $1.63 \%$ Urea & 0 & 0 & 16.3 & $\sim 0$ \\
\hline
\end{tabular}

${ }^{a}$ The quantities of the chemicals are in gram units; the final volume is one liter. 


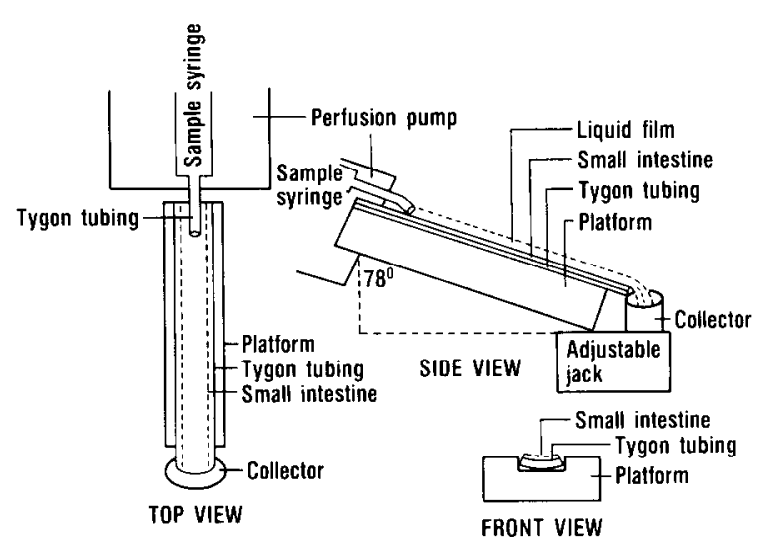

Fig. 1. Schematic diagram of the falling liquid film perfusion system.

Tygon flute was perfused for $10 \mathrm{~min}$ with the identical buffer solution and flow rate used in the ensuing experiment. In the next $2 \mathrm{~min}$, samples of the effluent solution were collected and quantified for background concentration of particles. Preliminary studies revealed a constant sloughing of an extraneous substance, presumably mucus, with time.

To disperse the latex particles, the diluted suspension was sonicated for $30 \mathrm{~s}$ in a bath sonicator and then transferred to the syringe for the perfusion experiment to follow. Here, the particle concentration is about $5 \times 10^{6}$ per ml.

Studies were carried out in which the intestinal length, ionic strength and flow rate were varied. The extent of adsorption of particles was quantified by comparing the steady-state inflow and outflow concentration of particles. One-half $\mathrm{ml}$ samples of the effluent suspensions were collected throughout time wherein $400 \mu \mathrm{l}$ was transferred to a beaker containing $50 \mathrm{ml}$ normal saline and counted by the Coulter counter. Corrections of particle concentrations accounted for mucus background and flocculation.

After the experiment was carried out for a period sufficient to assure that steady-state conditions were achieved, the syringe containing the suspension was replaced by another syringe containing buffer solution. The intes- tine was then perfused to wash out essentially the non-adsorbed particles and mucus background.

To determine the extent of flocculation of particles in the syringe throughout the experiment, samples were obtained at the beginning and end of the experiment and quantified by the Coulter counter.

\section{Determination of linear flow velocity in the falling liquid film}

The apparatus for this study was similar to that described in the falling liquid film method. The only difference was that two syringes were used in conjunction with a single-drive dual syringe pump. A $10 \mathrm{ml}$ syringe was used for the buffered perfusion solution, and a $1 \mathrm{ml}$ syringe, whose outlet was positioned $0.5 \mathrm{~cm}$ below the outlet of the $10 \mathrm{ml}$ syringe, was used for the sample solution which contained $\left[{ }^{3} \mathrm{H}\right]-\mathrm{PEG}$ 4000 , a nonabsorbable marker dissolved in $\mathrm{pH}$ 7.5 buffer solution.

With the aid of the pump, the fluid stream along the length of intestinal tissue was established with the perfusion solution from the 10 $\mathrm{ml}$ syringe at rates ranging from 0.1 to 0.5 $\mathrm{ml} / \mathrm{min}$. The time at which the $\left[{ }^{3} \mathrm{H}\right]$-PEG 4000 solution from the $1 \mathrm{ml}$ syringe entered the established fluid stream was taken as time zero. It should be pointed out that the flow rates from the $1 \mathrm{ml}$ syringe were about one-tenth of the flow rates from the $10 \mathrm{ml}$ syringe. Samples were collected every $5 \mathrm{~s}$ when the flow rate was 0.51 $\mathrm{ml} / \mathrm{min}$ and every $10 \mathrm{~s}$ for flow rates of 0.103 and $0.206 \mathrm{ml} / \mathrm{min}$. Thereafter, $20 \mu \mathrm{l}$ of each collected sample was transfered to $10 \mathrm{ml}$ ACS scintillation cocktail (Amersham, Arlington Heights, IL) and assayed by a liquid scintillation counter (Beckman LS-9000). The counts in cpm were plotted against time in which the midpoint of the sampling time interval was taken. 


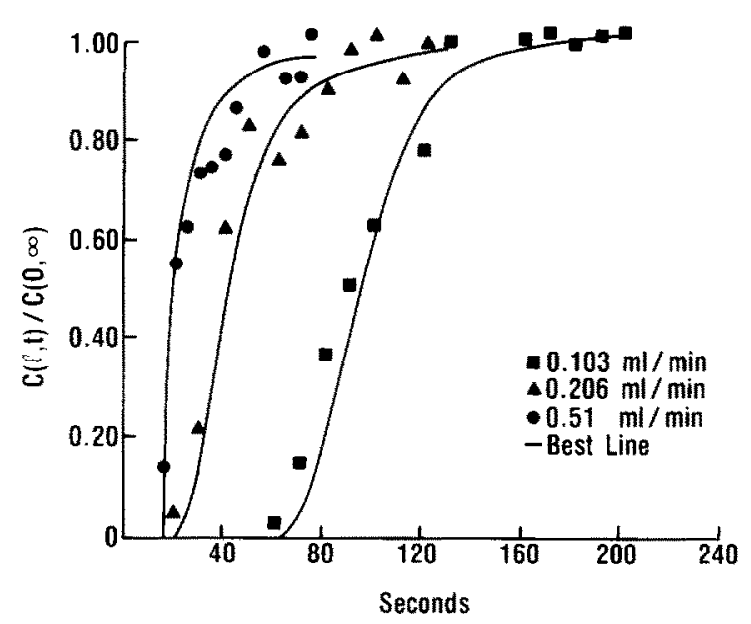

Fig. 2. The determination of average transit time in a 42 $\mathrm{cm}$ intestinal segment by using $\left[{ }^{3} \mathrm{H}\right]-\mathrm{PEG} 4000$ as a marker.

\section{RESULTS}

\section{Characterization of the flow velocities of the falling film method}

To characterize the flow of fluid under different pump flow rates in the falling liquid film system, flow velocities were determined from mean transit time measurements employing the nonabsorbable $\left[{ }^{3} \mathrm{H}\right]$-PEG 4000 marker in $\mathrm{pH}$ 7.5 phosphate-saline solution. The time course in the changes in concentration of PEG 4000 collected at the end of $42 \mathrm{~cm}$ rat intestinal segments for a variety of flow rates is shown in Fig. 2 . The concentration changes were compared with the PEG 4000 concentration entering the intestinal segment from an infinite reservoir.

The curves are sigmoidal and characteristic of a nonabsorbable marker. They may be described by

$$
\frac{C(l, t)}{C(0, \infty)}=0.5 \operatorname{erfc}\left[\frac{l-\beta t}{2 \sqrt{\alpha t}}\right]
$$

where $C(l, t)=$ concentration at distance $l$ at time $t ; C(0, \infty)=$ concentration of the infinite reservoir, $\alpha=$ axial dispersion coefficient, $\mathrm{cm}^{2} / \mathrm{s}$; $\beta=$ linear flow velocity, $\mathrm{cm} / \mathrm{s}$. As can be readily seen, the mean transit time is related to length and flow velocity by: $<t>=l / \beta$

for which

$C(l,<t>) / C(0, \infty)=0.5$

At steady-state, $C(l, t)$ is equal to $C(0, \infty)$.

Table 2 gives the estimates of the mean transit time, axial dispersion coefficient, linear flow velocity and their relation to the bulk flow rate. It is seen in Fig. 3 , that the flow velocity is linearly related to the flow rate wherein a fivefold change in flow rate from 0.103 to 0.51 $\mathrm{ml} / \mathrm{min}$ resulted in a five-fold increase in velocity from 0.446 to $2.113 \mathrm{~cm} / \mathrm{sec}$. Since all of the phosphate-saline-urea buffer solutions, whose compositions are found in Table 1 , have the same viscosities of $0.89 \mathrm{mPa} \cdot \mathrm{s}$ at $25^{\circ} \mathrm{C}$, their flow velocities should be identical.

The thickness of the fluid stream may be estimated using the following relationship between the flow velocity $\beta$ and bulk flow rate $Q$ :

$\beta=Q / w h^{\prime}$

where $w h$ ' is the cross-sectional area of a thin rectangular slab of liquid of width $w$ and thickness $h^{\prime}$. With $w=0.7 \mathrm{~cm}, h^{\prime}$ is found to be 54 $\mu \mathrm{m}$.

\section{Stability of particle surfaces}

To ascertain the stability of the surface properties of plain and polymer-coated particles, the zèta potentials of the particle systems were followed with time. During the weeks of storage in distilled, deionized water in a cellophane dialysis bag, the zèta potentials of the purified latex particles remained constant: PVT at $-70 \mathrm{mV}$ and hydroxylated Dynosphere at $-73 \mathrm{mV}$.

The surface stability of polymer-coated particles prepared daily was assessed after $150 \mu \mathrm{l}$ of the polymer-coated latex master suspension was transferred to $12 \mathrm{ml}$ of iso-osmotic, $\mathrm{pH} 7.5$ buffer solution containing varying $\mathrm{NaCl}$ concentrations and $12 \mathrm{ml}$ of iso-osmotic $1.63 \%$ urea in water. The zèta potential versus time plots 
TABLE 2

Quantitative characteristics of fluid of flow of the liquid film system

\begin{tabular}{lllll}
\hline $\begin{array}{l}\text { Flow rate } \\
\mathrm{ml} / \mathrm{min}\end{array}$ & $\begin{array}{l}\text { No. of } \\
\text { expts. }\end{array}$ & $\begin{array}{l}\text { Mean transit time (s) } \\
\text { over 42 cm length } \\
\text { (s.d.) }\end{array}$ & $\begin{array}{l}\text { Flow velocity cm/s } \\
\text { mean (s.d.) }\end{array}$ & $\begin{array}{l}\text { Axial dispersion } \\
\text { coefficient } \mathrm{cm}^{2} / \mathrm{s}\end{array}$ \\
\hline 0.103 & 3 & $94.8(9.7)$ & $0.45(0.04)$ & 0.065 \\
0.206 & 2 & $41.5(3.1)$ & $1.01(0.08)$ & 0.26 \\
0.51 & 2 & $20.0(2.4)$ & $2.11(0.25)$ & 0.65 \\
\hline
\end{tabular}

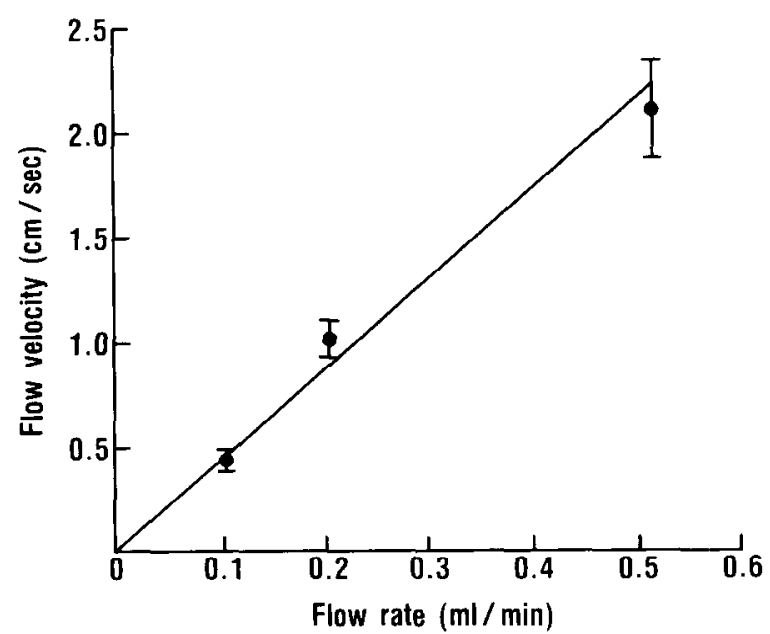

Fig. 3. Linear flow velocity of perfusion buffer solution at the different fluid flow rates.

in Fig. 4 of the particle systems in solutions varying in ionic strength indicate the permanency of the adsorbed polymer layer over a period of $80 \mathrm{~min}$. Thus, subsequent flocculation kinetic and intestinal adsorption studies could be carried out without concern of significant desorption of the polymer coat.

\section{Kinetics of flocculation of particle systems}

In order to delineate the loss of particles from an essentially monosized suspension due to flocculation from particle losses due to adherence to mucus, the flocculation tendencies of the various particle systems were assessed under perikinetic flocculation (diffusion-controlled) conditions with the Coulter counter. The floc- culation kinetic studies were carried out in varying ionic strength solutions.

The Smoluchowski-Fuch flocculation theory for an essentially monodispersed, dilute suspension applies here [5] wherein the rate is a second order kinetic process. Thus,

$\mathrm{d} N / \mathrm{d} t=-K N^{2}$

and, subsequently,

$1 / N=1 / N_{0}+K t$

where $N=$ number concentration of particles at time $t ; N_{0}=$ initial number of particles per ml; $K=$ second order flocculation rate constant, $\mathrm{cm}^{3} / \mathrm{s}$. The rate constant is further expressed by

$$
K=4 k_{\mathrm{B}} T / 3 \eta W
$$

where $k_{\mathrm{B}}=$ Boltzmann constant, $1.38 \times 10^{-16}$ $\mathrm{ergs} / \mathrm{K} ; T=$ absolute temperature, $\mathrm{K} ; \eta=$ viscosity of the medium, poise; $W=$ Fuch stability factor wherein $W \geq 1.0$. When $W=1.0$ for a dilute suspension in water at $25^{\circ} \mathrm{C}$ in which $\eta=0.8937 \times 10^{-2}$ poise, the theoretical maximum rate constant $K_{\max }$ is $6.2 \times 10^{-12} \mathrm{~cm}^{3} / \mathrm{s}$. In slow flocculation cases, $K_{\max }$ is reduced by a factor of $1 / W$.

Figure 5 shows the linear Smoluchowski-type plots of the flocculation of noncoated and polybrene-coated hydroxylated Dynosphere particles at varying ionic strengths from which the rate constants are obtained from the slopes. These plots are typical of the other particle systems. Table 3 summarizes the results of all particle systems in terms of their rate constants as 


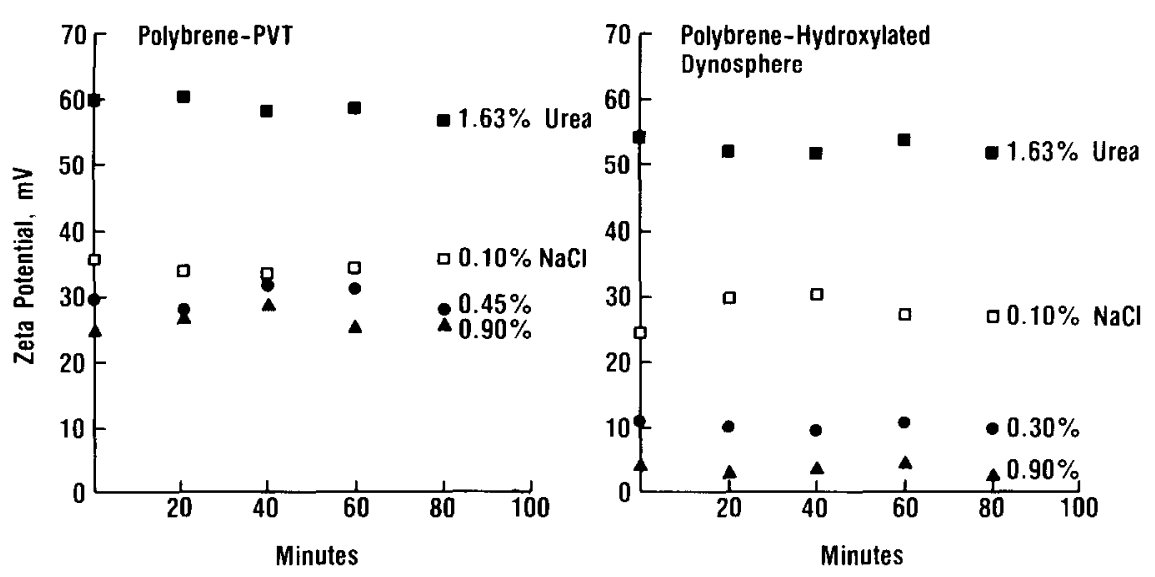

Fig. 4. Stability of zèta potentials of polybrene-coated PVT and hydroxylated Dynosphere latex particles in various ionic strength buffer solutions.
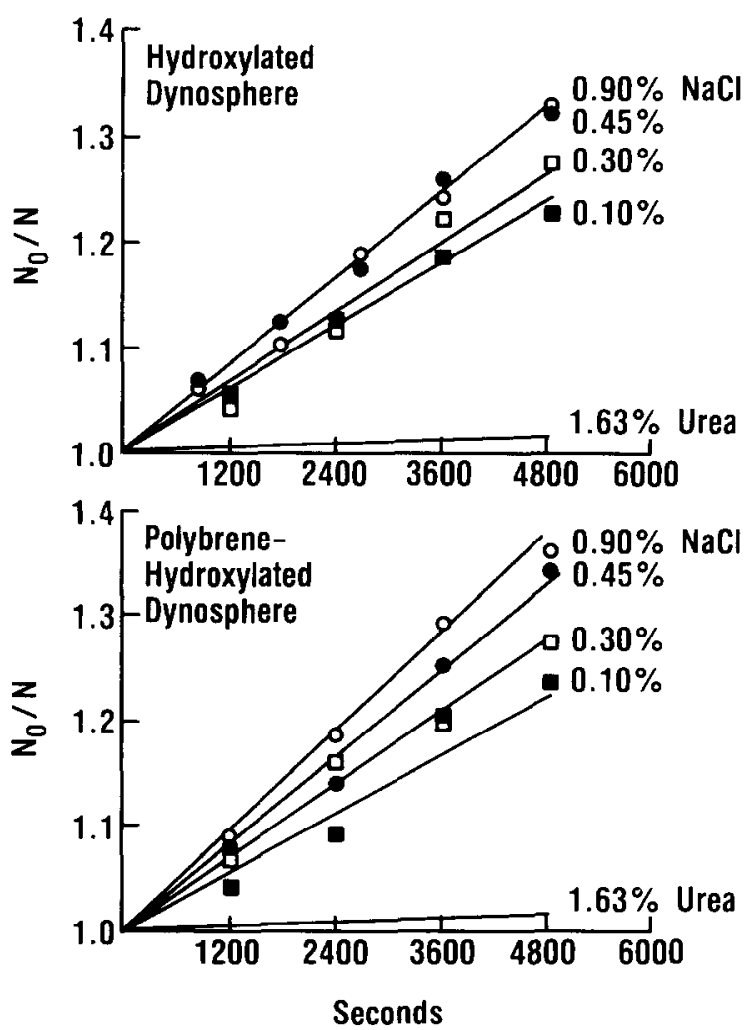

Fig. 5. Smoluchowski-type plots of the flocculation kinetics of noncoated and polybrene-coated hydroxylated Dynosphere particles in varying ionic strength solutions. a function of ionic strength, while Table 4 gives their corresponding zeta potentials at each ionic strength. The zèta potentials were determined with a laser illuminated, electrophoretic mobility instrument and the use of the Smoluchowski equation:

$$
\text { Z.P. }=\frac{4 \pi \eta V_{\mathrm{e}}}{\epsilon E} \times\left(9 \times 10^{4}\right)
$$

where Z.P. = zèta potential, volt; $\eta=$ viscosity of the medium, poise; $V_{\mathrm{e}}=$-velocity of the particle, $\mathrm{cm} / \mathrm{s} ; \epsilon=$ dielectric constant of the medium; $E=$ applied potential gradient, volt $/ \mathrm{cm}$.

As can be seen, PVT and hydroxylated Dynosphere particles are intrinsically negatively charged and, when neutralized with the positively charged, polybrene polymer coat, the particles become positively charged. In the zero ionic strength solution containing $1.63 \%$ urea in water, the zèta potentials are high. They tend to decrease as the ionic strength is increased. Correspondingly, the flocculation rate constants are small in $1.63 \%$ urea solution and generally increase with increasing ionic strength. In comparing the PVT and hydroxylated Dynosphere particle systems (uncoated and polybrene-coated particles), the flocculation constants tend to arrive at the maximum plateau value of approximately $6 \times 10^{-12} \mathrm{~cm}^{3} / \mathrm{s}$ 
TABLE 3

Summary of flocculation rate constants of various particle systems and ionic strength ${ }^{a}$ at $25^{\circ} \mathrm{C}$

\begin{tabular}{|c|c|c|c|c|c|}
\hline \multirow[t]{2}{*}{ Particle system } & \multicolumn{5}{|c|}{ Rate constant $\times 10^{12} \mathrm{~cm}^{3} / \mathrm{s}$ (s.d.) } \\
\hline & $1.63 \%$ Urea & $0.1 \% \mathrm{NaCl}$ & $0.3 \% \mathrm{NaCl}$ & $0.45 \% \mathrm{NaCl}$ & $0.9 \% \mathrm{NaCl}$ \\
\hline Polyvinyltoluene Latex & $\sim 0$ & $1.07(0.12)$ & $1.76(0.22)$ & $3.08(0.12)$ & $3.25(0.14)$ \\
\hline $\begin{array}{l}\text { Polybrene-coated } \\
\text { polyvinyltoluene latex }\end{array}$ & $\sim 0$ & $1.10(0.49)$ & $2.30(0.58)$ & $2.80(0.30)$ & $3.38(0.08)$ \\
\hline Hydroxylated Dynosphere & $0.29(0.08)$ & $3.96(0.20)$ & $6.16(0.59)$ & $6.21(0.28)$ & $6.68(0.56)$ \\
\hline $\begin{array}{l}\text { Polybrene-coated } \\
\text { hydroxylated Dynosphere }\end{array}$ & $0.24(0.04)$ & $4.67(0.67)$ & $5.00(0.33)$ & $5.72(0.41)$ & $6.02(0.26)$ \\
\hline
\end{tabular}

${ }^{a} \mathrm{All} \mathrm{NaCl}$ solutions contained $7.5 \mathrm{~m} M$ phosphate buffer at $\mathrm{pH} 7.5$.

TABLE 4

Summary of zèta potentials of various particle systems and ionic strength ${ }^{\mathrm{a}}$ at $25^{\circ} \mathrm{C}$

\begin{tabular}{lrrrrr}
\hline Particle system & \multicolumn{3}{l}{ Zèta potential mV (s.d.) } & & \\
\cline { 2 - 6 } & $1.63 \%$ Urea & $0.1 \% \mathrm{NaCl}$ & $0.3 \% \mathrm{NaCl}$ & $0.45 \% \mathrm{NaCl}$ & $0.9 \% \mathrm{NaCl}$ \\
\hline Polyvinyltoluene latex & $-73.5(0.9)$ & $-54.6(1.9)$ & $-47.0(1.6)$ & $-40.8(0.7)$ & $-32.3(1.8)$ \\
Polybrene-coated & $59.5(1.8)$ & $34.4(1.1)$ & $29.6(2.2)$ & $29.1(1.7)$ & 265.6 \\
& & & & & $(2.0)$ \\
$\quad$ polyvinyltoluene latex & & & & & \\
Hydroxylated Dynosphere & $-72.6(1.5)$ & $-23.8(1.6)$ & $-19.2(0.7)$ & $-13.0(0.8)$ & $-9.4(1.5)$ \\
Polybrene-coated & $53.2(1.7)$ & $27.5(2.4)$ & $10.2(0.7)$ & $5.5(1.2)$ & $3.3(1.5)$ \\
$\quad$ hydroxylated Dynosphere & & & & & \\
\hline
\end{tabular}

${ }^{a} \mathrm{All} \mathrm{NaCl}$ solutions contained $7.5 \mathrm{mM}$ phosphate buffer at $\mathrm{pH} 7.5$.

when the absolute values of the zeta potentials are about $15 \mathrm{mV}$ and less. This is the situation in which the electrical barrier between approaching particles is sufficiently reduced so that the collision probability is essentially unity and the maximum Smoluchowski rate constant is attained [6]. It is expected that the rates will increase as the zèta potentials of the PVT and polybrene-coated PVT particles are reduced from $\sim|30 \mathrm{mV}|$ at $0.9 \% \mathrm{NaCl}$ by further additions of $\mathrm{NaCl}$, but this was not pursued since the suspensions would be hypertonic and could not be readily used in subsequent studies with intestinal tissue strips.

\section{Intestinal adsorption of polybrene-coated PVT latex systems}

Figure 6 shows that about $100 \%$ of the plain PVT particles suspended in various ionic strength solutions were recovered after they passed through $55 \mathrm{~cm}$ intestinal segment. There appears to be only modest increases in the percent of particles adsorbed on the mucous surface as the ionic strength of the suspension medium is increased. These results provide the baseline upon which the adhesion of polymercoated PVT particles onto mucus can be compared. 


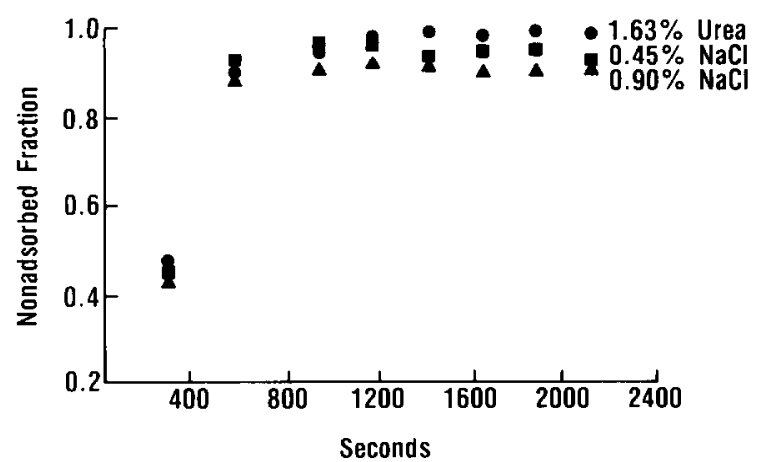

Fig. 6. Nonadsorbed fraction of plain PVT particles in 55 cm intestinal segment versus time. The particles were dispersed in solutions varying in ionic strength and the flow rate was $0.206 \mathrm{ml} / \mathrm{min}$.

Figures 7 and 8 represent the typical profiles of the change in the outflow to inflow concentration ratio of polybrene-coated particles with time as a function of intestinal length, bulk flow rate, and buffer ionic strength. The plateau region is the steady-state fraction of nonadsorbed particles remaining along the intestinal segment. It is seen in Fig. 8 that there was a sharp decrease in the fraction of nonadsorbed particles remaining during the washout phase of the experiments. This was accomplished by simultaneously stopping the pump drive to the syringe containing the particle suspension and initiating the pump drive to the syringe containing buffered perfusion solutions. Outflow samples were collected at $20 \mathrm{~s}$ intervals when the flow rate was $0.51 \mathrm{ml} / \mathrm{min}$ and $90 \mathrm{~s}$ intervals for the flow rate of $0.103 \mathrm{ml} / \mathrm{min}$. The fraction approached zero within a time period comparable to the expected transit time of nonadsorbed particles at the given flow rates. This infers that the particles which were adsorbed on the mucus of the intestinal surface remained essentially adsorbed in the washout process. Qualitatively, one can observe white patches of adsorbed particles.

In Fig. 9, the semilogarithmic plots of the nonadsorbed fraction of polybrene-coated particles versus intestinal length are found to be essentially linear at all flow rates employed. At any given flow rate, the nonadsorbed fraction

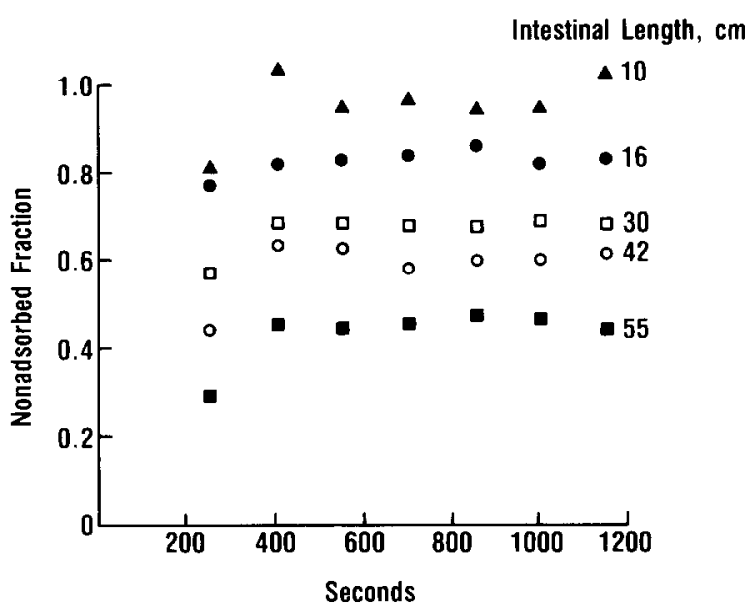

Fig. 7. Nonadsorbed fraction of polybrene-coated PVT particles versus time at various intestinal lengths. The particles were dispersed in $\mathrm{pH} 7.5$ buffer containing $0.9 \% \mathrm{NaCl}$ and the flow rate was $0.206 \mathrm{ml} / \mathrm{min}$.

decreases with increasing intestinal length and, correspondingly, the fraction of particles adsorbed increases with length. It is observed that the fraction adsorbed is higher with decreasing flow rates or lower with increasing flow rates.

To gain an understanding of the adsorption phenomenon, experiments were centered on the flow of plain and coated particles and concurrent adsorption along a $55 \mathrm{~cm}$ intestinal length

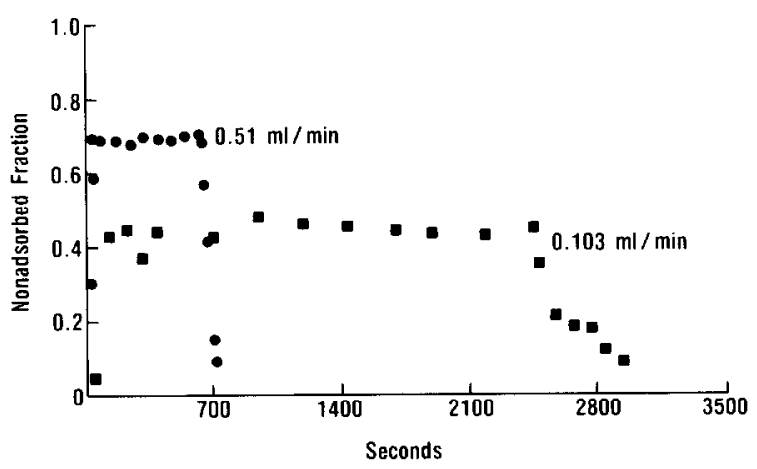

Fig. 8. Nonadsorbed fraction of polybrene-coated PVT particles in $55 \mathrm{~cm}$ intestinal length versus time at various flow rates. The particles were dispersed in $\mathrm{pH} 7.5$ buffer with $0.9 \% \mathrm{NaCl}$. The mean transit times for the washout of particles are $159.3 \mathrm{~s}$ for the flow rate of $0.103 \mathrm{ml} / \mathrm{min}$ and 61.8 $\mathrm{s}$ for the flow rate of $0.51 \mathrm{ml} / \mathrm{min}$. 
and at $0.103 \mathrm{ml} / \mathrm{min}$ flow rate. The results are found in Table 5 which shows the interrelationship of the fraction adsorbed, ionic strength and mass transfer-adsorption coefficient $k$, which will be later explained. Figure 10 illustrates the relationships including the zèta potentials of the particles as a function of ionic strength. It is clear that adsorption between the positively charged polybrene-coated particles and the

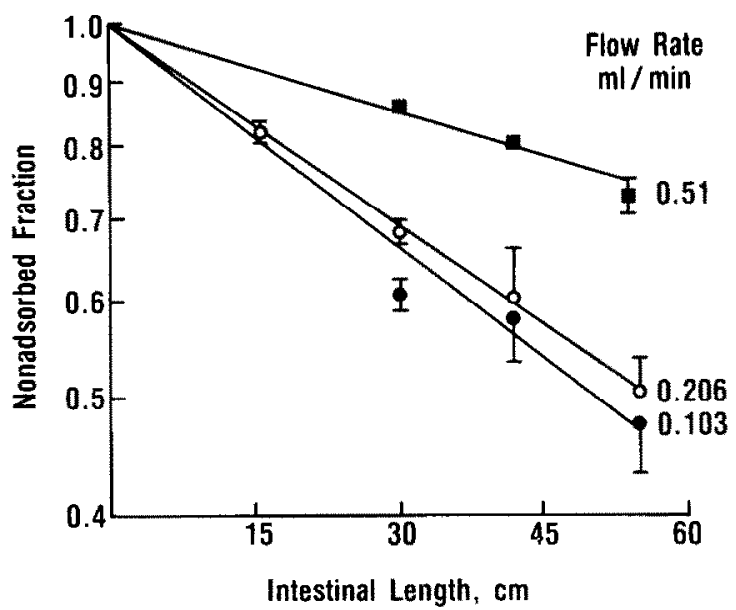

Fig. 9. Semilogarithmic relationship of nonadsorbed fraction of polybrene-coated PVT particles with intestinal length as a function of flow rate. The particles were dispersed in $\mathrm{pH} 7.5$ buffer containing $0.9 \% \mathrm{NaCl}$.
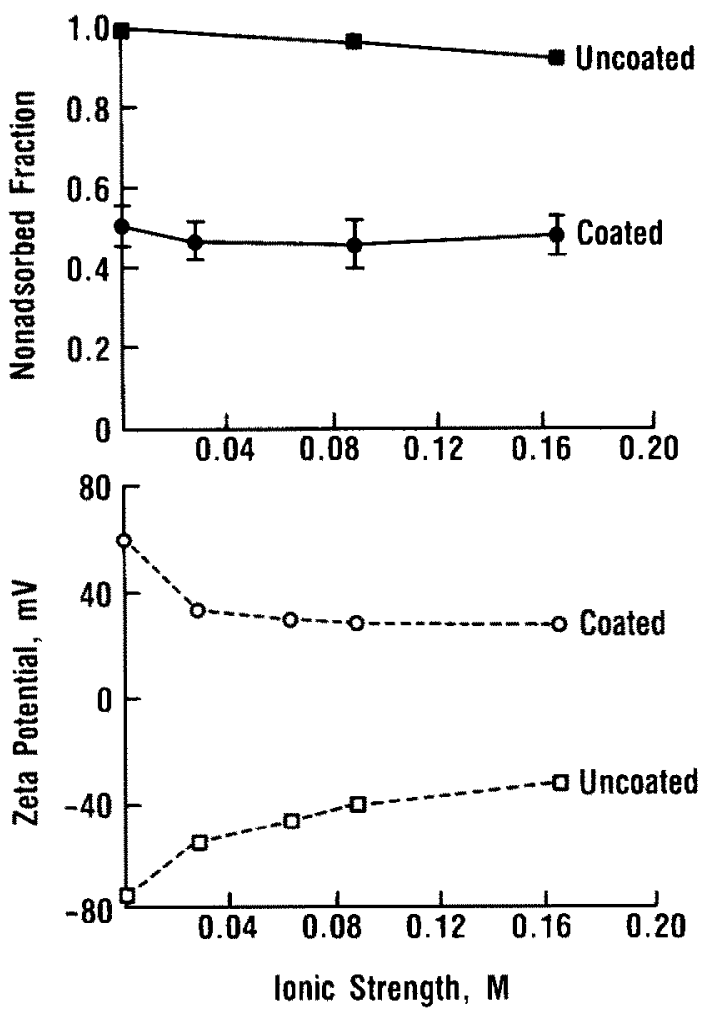

Fig. 10. Correlation of nonadsorbed fraction of plain PVT and polybrene-coated PVT particles in $55 \mathrm{~cm}$ intestinal length and at $0.103 \mathrm{ml} / \mathrm{min}$ with ionic strength and zèta potential.

\section{TABLE 5}

Mass transfer-adsorption coefficients, zèta potential and fraction adsorbed of polyvinyltoluene and polybrene-coated polyvinyltoluene latex particles as a function of ionic strength in a $55 \mathrm{~cm}$ intestinal segment and $0.103 \mathrm{ml} / \mathrm{min}$ flow rate

\begin{tabular}{|c|c|c|c|c|c|c|}
\hline \multirow[t]{2}{*}{ Particle system } & \multirow{2}{*}{$\begin{array}{l}\text { Ionic } \\
\text { strength } \\
(M)\end{array}$} & \multirow[t]{2}{*}{$\begin{array}{l}\text { No. of } \\
\text { expts }\end{array}$} & \multirow{2}{*}{$\begin{array}{l}\text { Fraction } \\
\text { adsorbed } \\
\text { mean (s.d.) }\end{array}$} & \multirow{2}{*}{$\begin{array}{l}k \times 10^{5} \\
\mathrm{~cm} / \mathrm{s} \\
\text { mean (s.d.) }\end{array}$} & \multicolumn{2}{|c|}{$\begin{array}{l}\text { Zèta potential } \\
(\mathrm{mV})\end{array}$} \\
\hline & & & & & Initial & Post \\
\hline $\begin{array}{l}\text { Polyvinyltoluene } \\
\text { latex }\end{array}$ & $\begin{array}{l}\sim 0 \\
0.082 \\
0.165\end{array}$ & $\begin{array}{l}1 \\
1 \\
1\end{array}$ & $\begin{array}{l}0.006 \\
0.048 \\
0.086\end{array}$ & $\begin{array}{l}0.03 \\
0.22 \\
0.40\end{array}$ & $\begin{array}{l}-73.5 \\
-40.8 \\
-32.3\end{array}$ & $\begin{array}{l}-23.1 \\
-26.5\end{array}$ \\
\hline $\begin{array}{l}\text { Polybrene-coated } \\
\text { polyvinyltoluene } \\
\text { latex }\end{array}$ & $\begin{array}{l}\sim 0 \\
0.028 \\
0.082 \\
0.165\end{array}$ & $\begin{array}{l}3 \\
2 \\
2 \\
2\end{array}$ & $\begin{array}{l}0.497(0.051) \\
0.528(0.046) \\
0.543(0.061) \\
0.524(0.046)\end{array}$ & $\begin{array}{l}3.08(0.47) \\
3.36(0.43) \\
3.51(0.59) \\
3.32(0.43)\end{array}$ & $\begin{array}{l}59.5 \\
34.4 \\
29.1 \\
26.6\end{array}$ & $\begin{array}{r}17.3 \\
8.3\end{array}$ \\
\hline
\end{tabular}


negatively charged mucous surface occurred as a result of electrostatic attraction. Although the positive zeta potentials of the coated particles decreased with increasing ionic strength, the percent adsorbed remained the same at about $53 \%$. In contrast, adsorption between plain PVT particles and mucus, both having negatively charged surfaces, is poor. In approaching the mucous surface, the PVT particles must apparently overcome the net potential energy barrier of electrostatic repulsion.

There are indications that the soluble and negatively charged mucus, which has desorbed from the intestinal mucous layer, are adsorbed to some extent on the particle surface. It is evidenced by the change in the zeta potentials before and after the particles have passed through the intestinal segment (Table 5). The net charge of the polybrene-coated particles is seen to be less positive due to the neutralization of the polybrene by the mucus. The charge on the uncoated latex particles seems to be determined by the adsorbed mucus.

\section{Intestinal adsorption of hydroxylated dynos- phere latex systems}

Figure 11 shows the fraction of nonadsorbed particles remaining in $55 \mathrm{~cm}$ intestinal length versus time plot for plain hydroxylated Dynosphere particles suspended in $0.165 \mathrm{M}$ ionic strength solution. The steady-state nonad- sorbed fraction in the plateau region increases as the flow rate is increased from 0.103 to 0.51 $\mathrm{ml} / \mathrm{min}$. The washout experiments with buffered perfusion solution show rapid clearances of the suspension with mean transit times comparable to the expected mean transit times of the fluid (see Table 3). There does not appear to be a slow desorption of particles from the mucous surface. Washout experiments were not performed with the polybrene-coated particles since the results are expected to be the same as that seen in Fig. 8 .

Studies were extended to determine the effect of slurry density on the adsorption behaviour of the particles (Table 6). The fraction adsorbed was not affected by particle concentrations ranging from $\sim(5$ to 14$) \times 10^{6}$ particles $/ \mathrm{ml}$, or volume fractions from $(0.7$ to 1.9) $\times 10^{-4}$.

In Table 7 and Fig. 12, it is shown that the fraction of plain hydroxylated Dynosphere particles adsorbed on the mucus lining the $55 \mathrm{~cm}$ intestinal segment from a dilute suspension flowing at $0.103 \mathrm{ml} / \mathrm{min}$ is dependent on ionic strength. The fraction adsorbed is seen to increase with increasing ionic strength. Correspondingly, the negative zèta potential rapidly approaches zero as the ionic strength goes from 0 to $0.165 \mathrm{M}$.

It is noteworthy that the hydroxylated Dynosphere and PVT particles, both being negatively charged and having about $-70 \mathrm{mV}$ in

\section{TABLE 6}

Percent adsorbed of hydroxylated dynosphere particles as a function of particle concentrations in $7.5 \mathrm{~m} M$ phosphate buffer $\mathrm{pH} 7.5$ with $0.9 \% \mathrm{NaCl}, 55 \mathrm{~cm}$ intestinal segment and $0.103 \mathrm{ml} / \mathrm{min}$ flow rate ${ }^{\mathrm{a}}$

\begin{tabular}{cll}
\hline $\begin{array}{l}\text { Initial particle concentration } \\
\text { No. of particles } / \mathrm{ml} \times 10^{-6}\end{array}$ & $\begin{array}{l}\text { Volume fraction } \\
\text { of particles } \times 10^{4}\end{array}$ & $\begin{array}{l}\text { Percent } \\
\text { adsorbed }\end{array}$ \\
\hline 4.87 & 0.69 & 52.8 \\
6.63 & 0.94 & 54.7 \\
9.32 & 1.32 & 57.2 \\
13.61 & 1.92 & 52.2 \\
\hline
\end{tabular}

axperiments were carried out over a 10 min steady-state period. 


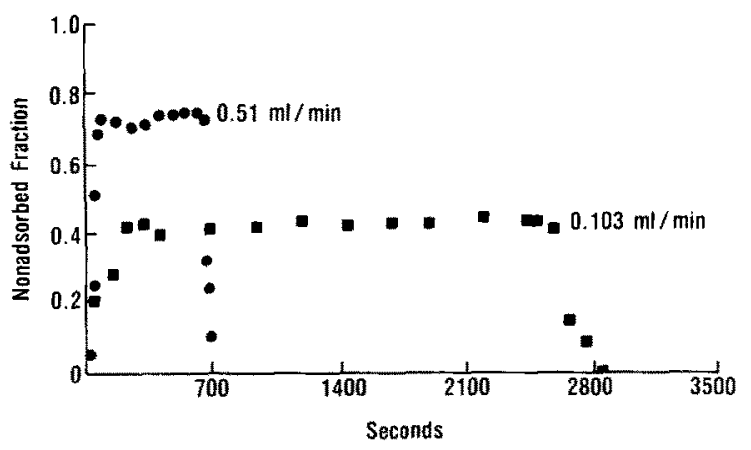

Fig. 11. Nonadsorbed fraction of plain hydroxylated Dynosphere particles in $55 \mathrm{~cm}$ intestinal length versus time at various flow rates. The particles were dispersed in $\mathrm{pH}$ 7.5 buffer with $0.9 \% \mathrm{NaCl}$. The mean transit times for the washout of particles are $200.6 \mathrm{~s}$ for the flow rate of 0.103 $\mathrm{ml} / \mathrm{min}$ and $27.6 \mathrm{~s}$ for the flow rate of $0.51 \mathrm{ml} / \mathrm{min}$.

$1.63 \%$ urea solution, are not adsorbed to the same extent under identical conditions of intestinal length, flow rate and ionic strength. For example, about $52 \%$ of the hydroxylated Dynosphere latex are adsorbed at $0.165 \mathrm{M}$ ionic strength as compared to $8.6 \%$ PVT latex adsorbed. 'There is, however, no apparent potential energy barrier to the approach of the Dynosphere particles toward the mucous sur- face as indicated by the nearly zero zèta potential at $0.165 M$ ionic strength; whereas, the electrostatic repulsion barrier is yet substantial for PVT particles whose zèta potential is -30 $\mathrm{mV}$.

The coated particles are adsorbed on mucus to the same extent at all ionic strengths despite the fact that the positive zeta potentials are depressed by increasing the $\mathrm{Cl}^{-}$counterion concentration. On the average, the fraction adsorbed is 0.53 and, to no surprise, is identical to that observed for polybrene-coated PVT particles. Since adsorption occurred by electrostatic attraction between the positively charged polybrene-coated particles and the negatively charged mucus, there is no potential energy barrier between them. It is also seen that the fraction adsorbed of the uncoated hydroxylated Dynosphere particles attain the same values as the polybrene-coated particles when the zèta potential is reduced to essentially zero at 0.165 $M$ ionic strength.

There appears to be some adsorption of free mucus on the plain latex particles. Although the zèta potential of the polybrene-coated particles was not determined after the particles passed

\section{TABLE 7}

Mass transfer-adsorption coefficients, zèta potential and fraction adsorbed of hydroxylated Dynosphere and polybrenecoated hydroxylated Dynosphere particles as a function of ionic strength in a $55 \mathrm{~cm}$ intestinal segment and $0.103 \mathrm{ml} / \mathrm{min}$ flow rate

\begin{tabular}{cllllll}
\hline Particle system & $\begin{array}{l}\text { Ionic } \\
\text { strength } \\
(M)\end{array}$ & $\begin{array}{l}\text { No. } \\
\text { of } \\
\text { expts }\end{array}$ & $\begin{array}{l}\text { Fraction } \\
\text { adsorbed } \\
\text { mean (s.d.) }\end{array}$ & $\begin{array}{l}k \times 10^{5} \\
\mathrm{~cm} / \mathrm{sec} \\
\text { mean (s.d.) }\end{array}$ & $\begin{array}{l}\text { Zèta potential } \\
(\mathrm{mV})\end{array}$ \\
\hline Hydroxylated & $\sim 0$ & 2 & $0.096(0.002)$ & $0.45(0.01)$ & -72.6 & -40.4 \\
Dynosphere & 0.028 & 4 & $0.339(0.024)$ & $1.85(0.16)$ & -23.8 & \\
& 0.062 & 3 & $0.343(0.046)$ & $2.05(0.03)$ & -19.2 & -18.4 \\
& 0.082 & 3 & $0.442(0.035)$ & $2.61(0.29)$ & -13.2 & \\
& 0.165 & 6 & $0.546(0.026)$ & $3.53(0.26)$ & -9.4 & \\
Polybrene-coated & $\sim 0$ & 2 & $0.581(0.049)$ & $3.90(0.52)$ & 53.2 & \\
hydroxylated & 0.028 & 2 & $0.506(0.074)$ & $3.18(0.69)$ & 27.5 & \\
Dynosphere & 0.082 & 2 & $0.497(0.075)$ & $3.09(0.66)$ & 5.5 & \\
\hline
\end{tabular}



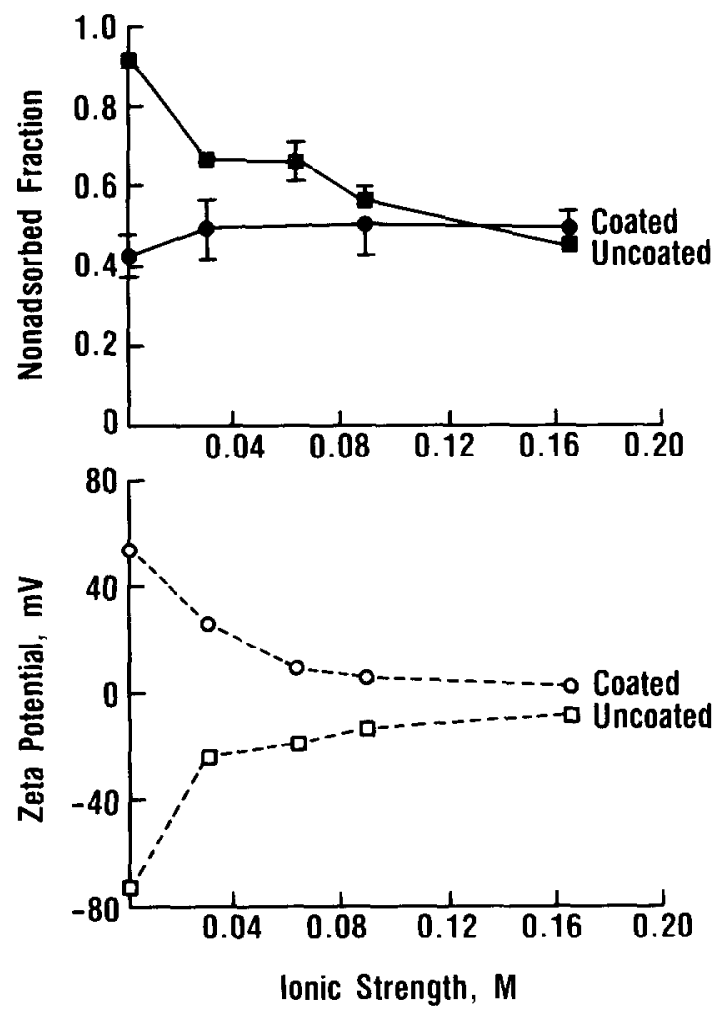

Fig. 12. Correlation of nonadsorbed fraction of plain hydroxylated Dynosphere particles and polybrene-coated particles in $55 \mathrm{~cm}$ intestinal length and at $0.103 \mathrm{ml} / \mathrm{min}$ flow rate with ionic strength and zèta potential.

through the intestinal strip, it was expected, as seen before in Table 5, that the adsorbed mucus would alter the zèta potential leaving a net positively charged particle surface.

\section{DISCUSSION}

\section{General assessment of the physical model}

The steady-state flow of a dilute suspension of micron-size particles in a thin film of water and the concurrent adsorption of particles on the mucous surface along an intestinal strip appear to follow, remarkably, the predicted trends found in the simultaneous flow of organic compounds in solution and intestinal absorp- tion $[1,7,8]$. The intestinal absorption model is based on the flow of a solute from an infinite solution reservoir through an intestinal segment and absorption by the mucosal membrane into the blood sink. The consequence is a steady-state concentration gradient in the intestinal lumen which is exponentially related with distance. The intestinal absorption model predicts that (a) the steady-state nonadsorbed fraction of solute in the intestinal lumen at any length should be independent of time and ( $b$ ) the logarithm of the steady-state nonadsorbed fraction decreases linearly with intestinal length and is inversely proportional to the flow rate.

The steady-state flow of a dilute suspension of micron-size particles across a volume element of a rectangular slab is equal to the flux of particles per unit crossectional area toward the mucous surface of an intestinal strip:

$\frac{Q}{w} \cdot \frac{\mathrm{d} N(x)}{\mathrm{d} x}=J$

$J=-k N(x)$

where $N(x)=$ particle concentration at distance $x$ along the intestinal strip, number of particles $/ \mathrm{ml} ; Q=$ bulk flow rate, $\mathrm{ml} / \mathrm{s} ; w=$ width of the flowing suspension, $\mathrm{cm} ; J=$ flux per unit area, number of particles $/ \mathrm{cm}^{2}-\mathrm{s} ; \quad k=$ mass transfer coefficient, $\mathrm{cm} / \mathrm{s}$. It follows that:

$\frac{N(l)}{N(0)}=\exp \left(-\frac{k w l}{Q}\right)$

where $N(0)$ and $N(l)$ are the particle concentrations entering the intestinal segment at $x=0$ from the infinite reservoir and leaving the segment at $x=l$, respectively. Upon rearrangement of eqn. 11, the mass transfer coefficient is readily calculated:

$k=-\frac{Q}{w l} \ln \left(\frac{N(l)}{N(0)}\right)$

Because $N(l) / N(0)$ is the nonadsorbed fraction of particles remaining along the intestinal strip, then 
Fraction Adsorbed $=1-N(l) / N(0)$

In accordance with the expectations of the adsorption model, the outflow to inflow particle concentration ratio versus time plots of all particle systems at the flow rates employed show a steady-state plateau region throughout the time course of the experiment (e.g. Figs. 6-8,11). It is also seen, in the case of polybrene-coated PVT latex particles (Fig. 9) that the semilogarithmic plots of the nonadsorbed fraction of particles versus intestinal length are found to be essentially linear at all flow rates employed and that the nonadsorbed fraction increases with increasing flow rate.

Unlike the situations of intestinal absorption, the effective area of the mucous surface occupied by adsorbed particles is not available for particle-mucus adsorption of other particles flowing from the infinite reservoir. Since this is the case, a particle concentration gradient in the flowing liquid film can exist only when the volume fraction of particles is very small, the surface area is relatively large and the total time course of the experiment is relatively short. This reasoning is supported by the fact that the plateau values of the $N(l) / N(0)$ versus time plots (Figs. 6-8,11) remained constant over a $40 \mathrm{~min}$ period and that the fraction of various particle systems adsorbed to the mucus did not change over a dilute particle concentration range of $4.5 \times 10^{6}$ to $13.6 \times 10^{6}$ particles per $\mathrm{ml}$, or volume fractions of $0.7 \times 10^{-4}$ to $1.9 \times 10^{-4}$ ('Table 6 ). Taking the most liberal situation for the flow and adsorption of hydroxylated Dynosphere particles along a $55 \mathrm{~cm}$ intestinal strip at a flow rate of $0.103 \mathrm{ml} / \mathrm{min}$ over a $40 \mathrm{~min}$ period, it is estimated that about $5 \%$ of the total surface area of the intestinal strip is occupied by adsorbed particles when the concentration is $13.6 \times 10^{6}$ particles per $\mathrm{ml}$. In most situations involving other particle systems and experimental conditions, it is estimated that no more than $3 \%$ of the surface area was covered by adsorbed particles. Although there remains the probability of particles in the fluid stream adhering to par-

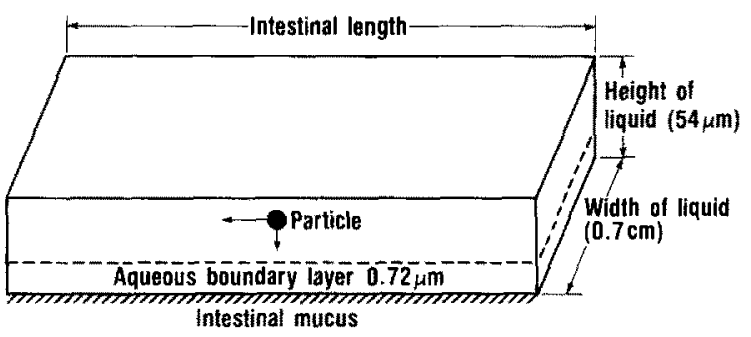

Fig. 13. Physical model for the diffusion of particles to mucous surface within a field of force and concurrent flow across the intestinal strip.

ticles previously adsorbed onto mucus, it is believed to be an insignificant occurrence as compared to the adsorption of particles on unoccupied areas of mucus surface.

The adsorbed particles appear to be tightly bound within the hydrodynamic shear conditions employed in the experiments. This is evidenced by the apparent lack of desorption of particles after the unbound particles have been washed out with the buffered perfusion solution (Figs. 8 and 11).

In summary, the experimental results indicate that the steady-state flow of a dilute, micron-size, particle suspension in a thin liquid film from an infinite suspension reservoir and the concurrent adsorption of particles on mucus along an intestinal strip can be described by the physical model in Fig. 13 and the mathematical expression previously described in eqn. 11 . The model assumes irreversible adsorption and the combination of a small volume fraction of particles and large surface area to accommodate particle-mucus interaction. The liquid film is $54 \mu \mathrm{m}$ thick which was determined by measurements of the flow velocities with the aid of a PEG-4000, a nonadsorbed and nonabsorbable marker.

\section{Mechanistic understanding of the mass transfer-adsorption kinetics}

The findings show that the fraction of positively charged polybrene-coated PVT and 
hydroxylated Dynosphere particles adsorbed on the negatively charged mucous surface is independent of the addition of sodium chloride. However, the fraction adsorbed of negatively charged particles (PVT and hydroxylated Dynosphere particles) are dramatically influenced by increases in electrolyte concentration. Stated in another way, the mass transfer coefficient $k$ values for the negatively charged particle systems increase with sodium chloride additions and approach a maximum value attained by the polybrene-coated particle systems.

In view of the experimental results, mass transfer coefficient may be described by:

$k=D / h W^{*}$

and, in turn, the mass transfer resistance is:

$R=1 / k=h W^{*} / D$

where $k=$ mass transfer coefficient, $\mathrm{cm} / \mathrm{s}$; $R=$ mass transfer resistance, $\mathrm{s} / \mathrm{cm}$; $D=$ diffusion coefficient of the latex particle, $\mathrm{cm}^{2} / \mathrm{s} ; h=$ thickness of the aqueous boundary layer, $\mathrm{cm} ; W^{*}=$ collision barrier factor, dimensionless.

The collision barrier factor is further defined by:

$W^{*}=\frac{1}{h} \int_{0}^{h} \exp \left(V(x) / k_{\mathrm{B}} T\right) \mathrm{d} x$

where $W^{*} \geq 1.0$ and $k_{\mathrm{B}} T=$ thermal energy, ergs; $V(x)=$ total potential of energy of interaction between the latex sphere and flat mucous surface, ergs. The total potential energy is the sum of the potential energies of electrical repulsion between the negatively charged particles and mucus, and attractive dispersion energies. Taking the logarithm of eqn. 15, one gets

$\ln R=\ln (h / D)+\ln W^{*}$

where $\ln W^{*}$ has been shown to be linearly related to the square root of the ionic strength $[9,10]$.

In terms of physical interpretation, eqns. 14-17 describe the diffusional step of the par- ticles within a field of force as the particles approach the mucous surface. The successful passage of a particle over the potential energy barrier is necessary for the collision and irreversible adsorption of the particle with the mucous surface. When there is no potential energy barrier, $W^{*}$ is unity and the diffusioncontrolled situation is achieved. Thus,

$k_{\max }=D / h$

$R_{\min }=h / D$

The values of the mass transfer coefficients for the particle systems in various ionic strength solutions are summarized in Tables 5 and 7 . The average $k_{\max }$, taken from the $k$ values of the polybrene-coated PVT and hydroxylated particle systems, is $3.3 \times 10^{-5} \mathrm{~cm} / \mathrm{s}$. With the diffusion coefficient of the $1.5 \mu \mathrm{m}$ radius particles in water at $37^{\circ} \mathrm{C}$ being $2.4 \times 10^{-9} \mathrm{~cm}^{2} / \mathrm{s}$ by the Stokes-Einstein relationship, the thickness of the thin hydrodynamic boundary layer within the liquid film of $54 \mu \mathrm{m}$ is estimated to be 0.72 $\mu \mathrm{m}$.

As indicated by the theoretical considerations found in eqn. 17, when the data in Table 7 is plotted in terms of the semilogarithmic change in the mass transfer resistance $R$ with the square root of the ionic strength $I$, the $R$ of the negatively charged hydroxylated Dynosphere particles is seen in Fig. 14 to decrease logarithmically with $\sqrt{I}$ and arrives at the ionic strength-independent, minimum resistance defined by the positively charged, polybrenecoated hydroxylated Dynosphere particles. The electrostatic interfacial resistance at nearly zero ionic strength is about 7 times greater than the diffusion-controlled resistance. As the ionic strength increases, the net electrical repulsion barrier is reduced. Since the distance for significant electrostatic repulsion between two charge surfaces of like signs is in the order of a single electrical double layer thickness, the distance is estimated by the Debye-Hückel eqn. [6] to be 20 to $8 \AA$ for ionic strengths ranging from 0.028 to $0.165 M$, respectively.

The surface fouling of particles by desorbed 


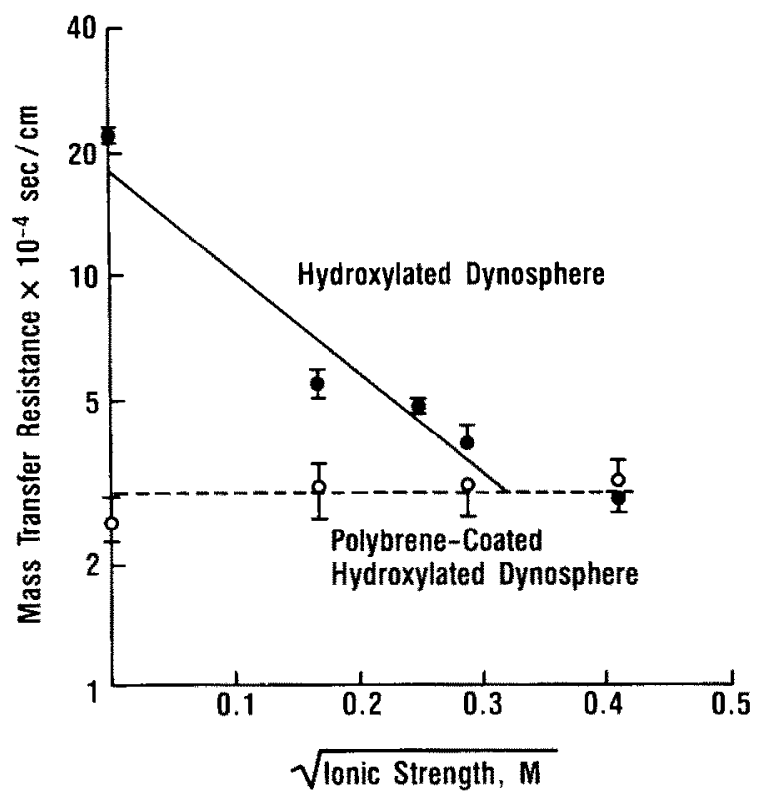

Fig. 14. Semilogarithmic relationship of mass transfer resistance and the square root of the ionic strength in the flow and adsorption of plain and polybrene-coated hydroxylated Dynosphere particles. Correlation coefficient of least square bold line is 0.95 .

mucus appears to have markedly decreased the capability of uncoated PV'T latices to adsorb on the intestinal surface, and to a much less extent on hydroxylated Dynosphere particles. Although both particles have negatively charged surfaces with zèta potentials of about $-70 \mathrm{mV}$ in water, mucus adsorption on the relatively hydrophobic PVT surface seems greater as compared to that on the less hydrophobic, hydroxylated Dynosphere surface. The adsorption of free mucus also occurred on polybrenecoated particles (Table 5), but the net result was a reduction in zèta potential which still remained on positive side. The constant sloughing of mucus from the intestinal surface along the intestinal strip seemed to be unavoidable, despite efforts to wash away loosely-held mucus. On the whole, mucus contamination of particle surfaces appear unfavorable in promoting the adhesion of particles on the intestinal mucus surface.

Studies are in progress on the simultaneous flow and adhesion of dextran, cellulose sulfate and mucous-coated latex particles on the intestinal surface.

\section{REFERENCES}

1 N.F.H. Ho, H.P. Merkle and W.I. Higuchi, Quantitative, mechanistic and physiologically realistic approach to the biopharmaceutical design of oral drug delivery system, Drug Dev. Ind. Pharm., 9 (1983) 1111-1184.

2 H. Park and J.R. Robinson, Bioadhesive polymers as platforms for oral-controlled drug delivery: Method to study bioadhesion, Int. J. Pharm., 19 (1984) 107-127.

3 H.S. Ch'ng, H. Park, P. Kelly and J.R. Robinson, Bioadhesive polymers as platforms for oral controlled drug delivery II: Synthesis and evaluation of some swelly, water-insoluble bioadhesive polymers, J. Pharm. Sci., 74 (1985) 399-405.

4 H. Park and J.R. Robinson, Physicochemical properties of water-insoluble polymers important to mucin /epithelial adhesion, J. Controlled Release, 2 (1985) $47-57$.

5 J.Th. Overbeek, Kinetics of flocculation, in: H.R. Kruyt (Ed.), Colloid Science, Elsevier, Amsterdam, The Netherlands, 1952, pp. 278-282.

6 J.Th. Overbeek, The interaction between colloidal particles, in: H.R. Kruyt (Ed.), Colloid Science, Elsevier, Amsterdam, The Netherlands, 1952, pp. 245-276.

7 G.E. Amidon, N.F.H. Ho, A.B. French and W.I. Higuchi, Predicted absorption rates with simultaneous bulk fluid flow in the intestinal tract, J. Theor. Biol., 89 (1981) 195-210.

8 I. Komiya, J.Y. Park, A. Kamani, N.F.H. Ho and W.I. Higuchi, Quantitative mechanistic studies in simultaneous fluid flow and intestinal absorption using steroid as model solutes, Int. J. Pharm., 4 (1980) 249-262.

9 N.F.H. Ho, S.L. Gupta and W.I. Higuchi, Theoretical treatment of cholesterol monohydrate dissolution in Renex-690/ionic surfactant systems based on a physical model approach, J. Colloid Interface Sci., 101 (1984) 544-553.

10 S. Gupta, W.I. Higuchi and N.F.H. Ho, Cholesterol monohydrate dissolution rate studies in aqueous micellar sodium chenodeoxycholate solutions, J. Pharm. Sci., 74 (1985) 1178-1183. 